\title{
ERRATUM \\ on the article 'A feasibility study of using composite reinforcement in transport and power industry structures' (doi:10.3846/16484142.2017.1342689)
}

The printed version of the article 'A feasibility study of using composite reinforcement in transport and power industry structures' by Egidijus Vanagas, Romualdas Kliukas, Ona Lukoševičiené, Pavlo Maruschak, Andrius Patapavičius and Algirdas Juozapaitis published in the research journal TRANSPORT 32(3): 321-329 contains mistakes on 327 p. incorrect Fig. 6 - numbers (1, 2, 3, 4 and 5) near lines are not presented:

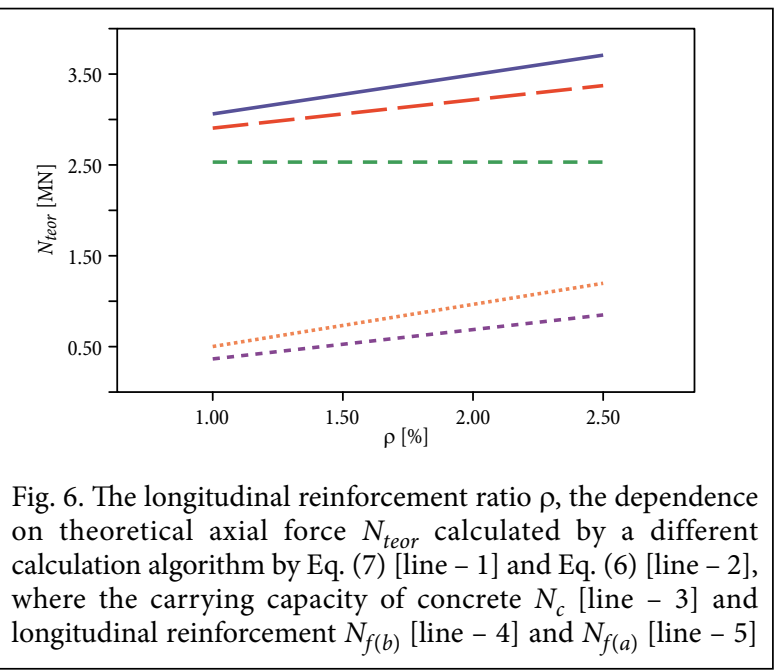

The Fig. 6 should be read as:

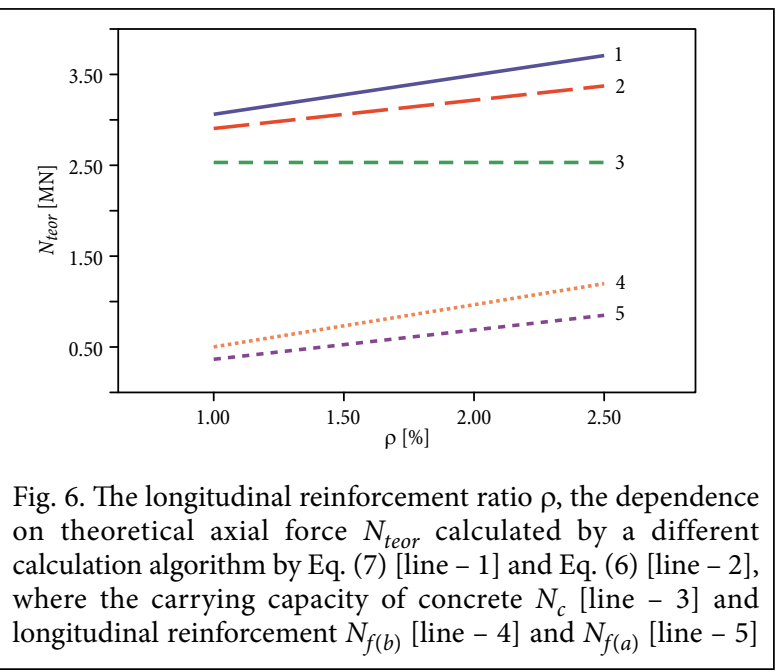

Corrected version of the article is available online (doi:10.3846/16484142.2017.1342689).

The Editorial Board of the TRANSPORT apologize to the authors of the article for this technical error. 